\title{
Analisis Video Comments to Video Views Ratio Youtube Pada 8 Rekomendasi iPhone Terbaik 2021
}

\author{
Yasintus Rionaldi Syukur \\ NIM : 19101320 \\ riosyukur20@gmail.com
}

\begin{abstract}
This study focuses on consumer interest in the 8 best iPhone recommendations in 2021 . Smartphone products issued by Apple Inc., which include the dimensions of the best iPhone. In this study, the smartphone product is not only seen as a product but also a brand, so that consumer interest becomes important in shaping the smartphone brand image. iPhone is a smartphone product that was first developed by the leader of the Apple Computer company, Steven Paul Jobs. a leader with a name identical to himself. This research uses qualitative research with descriptive research type. This research method is a case study of the best recommended iPhone 8 product in 2021. In collecting data, the researchers conducted an analysis of video comments to video views on youtube. Some of the theories used in this study include the dimensions of the smartphone brand, consumer interest, and several other relevant theories. Based on the results of the analysis, the researchers found that each informant had various perceptions of the dimensions of the smartphone brand as seen from the attributes of Apple products. Differences in perception occur because of differences in experience and background interests, habits, and other things from the informants who play a role in this perception process. Even so, the perception of informants who are iPhone consumers does not necessarily show the image of the iPhone product as a whole, because this study does not aim to generalize consumer perceptions.
\end{abstract}

\begin{abstract}
ABSTRAK
Penelitian ini berfokus pada minat konsumen terhadap 8 rekomendasi iPhone terbaik 2021. produk smarthphone yang dikeluarkan oleh Apple Inc, yang meliputi dimensi iPhone terbaik. Dalam penelitian ini, produk smarthphone tidak hanya dipandang sebagai sebuah produk namun juga sebuah brand, sehingga minat konsumen menjadi penting dalam membentuk citra brand smarthphone. iPhone merupakan produk smarthphone yang pertama kali dikembangkan oleh pemimpin perusahaan Apple Computer yaitu Steven Paul Jobs. seorang pemimpin dengan nama yang identik dengan dirinya. Penelitian ini menggunakan penelitian kualitatif dengan tipe penelitian deskriptif. Metode penelitian ini adalah studi kasus produk Rekomendasi 8 iPhone terbaik 2021. Dalam mengumpulkan data, peneliti melakukan analisis terhadap video comments to video views pada youtube. Beberapa teori yang digunakan dalam penelitian ini antara lain, dimensi brand smarthphoe, minat konsumen, serta beberapa teori lainnya yang relevan. Berdasarkan hasil analisis, peneliti menemukan bahwa setiap informan memiliki persepsi yang beragam terhadap dimesi brand smarthphone yang dilihat dari atribut produk Apple. Perbedaan persepsi terjadi karena adanya perbedaan pengalaman serta latar belakang
\end{abstract}


minat, kebiasaan, dan hal lain dari informan yang ikut berperan dalam proses persepsi ini. Meskipun begitu, persepsi informan yang merupakan konsumen iPhone, tidak serta merta menunjukkan citra dari produk iPhone secara keseluruhan, karena penelitian ini tidak bertujuan untuk mengeneralisasikan persepsi konsumennya.

Kata Kunci: 8 Rekomendasi iPhone terbaik 2021. 


\section{PENDAHULUAN}

Media sosial membuat individu satu dan lainnya dapat terhubung dan berbagi informasi yang dimilikinya. Menurut Henderson dan Bowley (2010, hal. 250), individuals use sosial media to connect to others and share personal information. Sehingga, penggunaan media sosial disini telah mengubah cara interaksi individu satu dengan yang lain dalam hal berkomunikasi.

Kemudahan yang didapatkan dari internet dan media sosial, membuatnya menjadi media interaksi yang memunculkan banyak sekali ruang - ruang virtual untuk berkomunikasi melalui teks, gambar, foto, audio juga video. Tidak hanya sebagai media interaksi, di dalam media sosial juga terdapat berbagai informasi dan hiburan dari seluruh penjuru dunia. Dengan bentuk komunikasi dua arah, membuat media sosial memberi kesempatan baik individu maupun kelompok untuk menjadi pengirim sekaligus penerima. Selain itu, media sosial memungkinkan penggunanya untuk menuangkan ide-idenya dan menghasilkan konten yang dapat dibagikan di akun media sosialnya. Di era media sosial seperti saat ini, membuat penggunanya menjadi seorang yang mengkonsumsi dan memproduksi konten yang ada, atau bisa disebut dengan prosumer.

Menurut Alvin Toffler dalam bukunya "The Rise of The Prosume", menyebutkan bahwa terdapat tiga gelombang dalam prosumer. Pertama, manusia hanya mengkonsumsi apa yang mereka dapat produksi, lalu bergeser pada gelombang kedua dimana masyarakat terbagi atas dua fungsi, produsen dan konsumen (Toffler, 1989, hal 266). Pada gelombang ini terdapat pergeseran makna produksi, dari production for use ke production for exchange. Meski setiap orang dapat menjadi seorang prosumer di media sosial, tetapi tidak semua orang mendapatkan kredibilitas sebagai prosumer. Sebagian dari pengguna media sosial berhasil menjadi prosumer yang mendapatkan kepercayaan dari pengguna lain, dan akhirnya menjadi terkenal di suatu media sosial tersebut. Beberapa 'labele untuk prosumer yang terkenal di media sosialnya, antara lain Youtuber di Youtube, Selebtweet di Twitter, dan Selebgram di Instagram.

Di era digital ini, keberadaan media sosial yang sangat dekat dengan manusia menjadikan pergeseran makna mengenai orang terkenal yang mempengaruhi proses komunikasi pemasan yang dahulunya dilakukan oleh para selebriti di media konvensional. Akhirnya, terjadi perubahan dalam diri konsumen yang menyebabkan konsumen lebih mudah terpengaruh atau mendapatkan influence dari seseorang yang terkenal di media sosial daripada seorang selebriti. Hal ini dikarenakan, konsumen yang menggunakan media sosial dapat merasa lebih dekat dan 'sama' dengan para influencer yang notabennya 'bukan selebriti' (dalam media konvensional) seperti mereka.

Tidak hanya menjadi seorang seleb, para selebgram kini juga banyak yang menjalakan bisnis dibidang yang sama. Setelah menjadi konsumer sebuah produk smarthphone, dan memiliki kredibilitas sebagai seorang penggemar brand smarthphone. Akhirnya membuat selebgram membuat produk smarthphone dengan namanya sendiri. Proses selebrifikasi ini adalah salah satu yang memungkinkan terciptanya sebuah brand, dengan nama yang identik pada produsennya (Smith \& Taylor, 2010, hal 262). Perubahan ini tidak hanya terjadi dalam diri konsumen, tetapi juga para pelaku bisnis, salah satunya yang bergerak dibidang smarthphone atau computer. Jika dahulu, produsen produk smarthphone merupakan 
perusahaan besar yang memiliki kredibilitas dibidangnya. Pada era digital seperti saat ini, banyak bermunculan brand-brand smarthphone lokal yang berasal bukan dari perusahaan besar tetapi dari pelaku bisnis sampai selebgram.

\section{TINJAUAN PUSTAKA}

Perkembangan bidang teknologi saat ini terjadi begitu pesat. Melalui perkembangan yang terjadi dari waktu ke waktu menimbulkan maraknya smarthphone-smarthphone serta platform smarthphone yang bermunculan akhir-akhir ini. smarthphone yang sangat diminati oleh masyarakat saat ini diantaranya adalah iPhone 8, iPhone 12, iPhone 12 Promax dan masih banyak jenis iPhone yang lainnya. Seiring berjalannya waktu, platform smarthphone tersebut dapat menjadi candu bagi kalangan masyarakat. Tidak hanya kalangan remaja yang menggunakan smarthphone media, orang tua bahkan anak-anak juga aktif menggunakan smarthphone media tersebut.

Di Indonesia, fenomena anak muda dalam menggunakan iPhone menunjukan antusiasme yang sangat massif. Meraka berlomba membangun identitas demi mendapatkan citra yang diinginkan, seperti dipuji dan dikenal oleh banyak orang (Wijaya and Mashud 2020) . iPhone semakin populer sejak diluncurkan tahun 2007. Bahkan iPhonetelah mencetak berbagai macam prestasi, salah satunya yaitu menyalip pendapatan iklan digital di negatanya yaitu pendapat Bukalapak. iPhone tidak hanya digunakan untuk membuat konten video dengan tujuan sebagai konten youtube. iPhone juga dapat dijadikan peluang bagi brand atau perusahaan sebagai platform smarthphone marketing. Penelitian menyatakan bahwa iPhone berpengaruh positif dan signifikan terhadap minat beli atau berbelanja secara online. Sehingga dengan ini, iPhone mampu memberikan peluang yang sangat tinggi bagi perusahaan-perusahaan dalam melakukan digital marketing.

\section{METODE PENELITIAN}

Penelitian ini menggunakan metode eksploratif kuantitatif untuk mengetahui kredibilitas dari performa iPhone 8 Rekomendasi iPhone terbaik 2021. Metode eksploratif merupakan penelitian yang memiliki tujuan untuk melakukan eksplorasi atau memperdalam pengetahuan ataupun ide-ide baru mengenai suatu hal yang baru, guna merumuskan permasalahan secara terperinci (Maryam, Isrok'atun, and Aeni 2016). Tujuan dari penelitian ini yaitu mengetahui nilai kredibillitas dari performa iPhone 8 Rekomendasi iPhone terbaik 2021. Ada beberapa langkah yang harus dilakukan dalam penelitian ini, sehingga mampu menemukan peringkat pertama rekomendasi iPhone 2021 yang memiliki performa terbaik. Langkah-langkah yang dilakukan pada penelitian ini, diantaranya yaitu :

\section{Melakukan Eksplorasi Pada Website Untuk Menentukan Objek yang Akan Dianalisa.}

Eksplorasi ini dilakukan pada beberapa halaman website yang menyediakan informasi mengenai objek yang akan di teliti. Setelah ekslorasi selesai dilakukan, sehinggaditemukan nama-nama vendor smartphone yang akan dijadikan objek analisa. Setelah melakukan eksplorasi pada halaman website, maka langkah selanjutnya yaitu mencari nama akun dari masing-masing vendor smartphone. Pastikan semua vendor memiliki akun pada masing-masing jenis iPhone.

\section{Menghitung Nilai Rata-Rata Variable Dari Top 5 Vendor Smartphone di}




\section{Indonesia.}

Pada langkah ini, peneliti menghitung nilai variable video comments dan variable video views. Variabel merupakan sesuatu yang memiliki nilai bervariasi dimana nilai tersebut dapat dijadikan sebagai dasar untuk empat data yang berbeda seperti rasio, skala, ordinal, nominal dan internal (Rankuti 2015) . Untuk menghitung nilai rata-rata dari variabel video comments dan variabel video views yaitu dengan cara mengambil minimal 10 postingan kemudian di hitung sehingga menemukan nilai rata-rata dari masing-masing variabel.

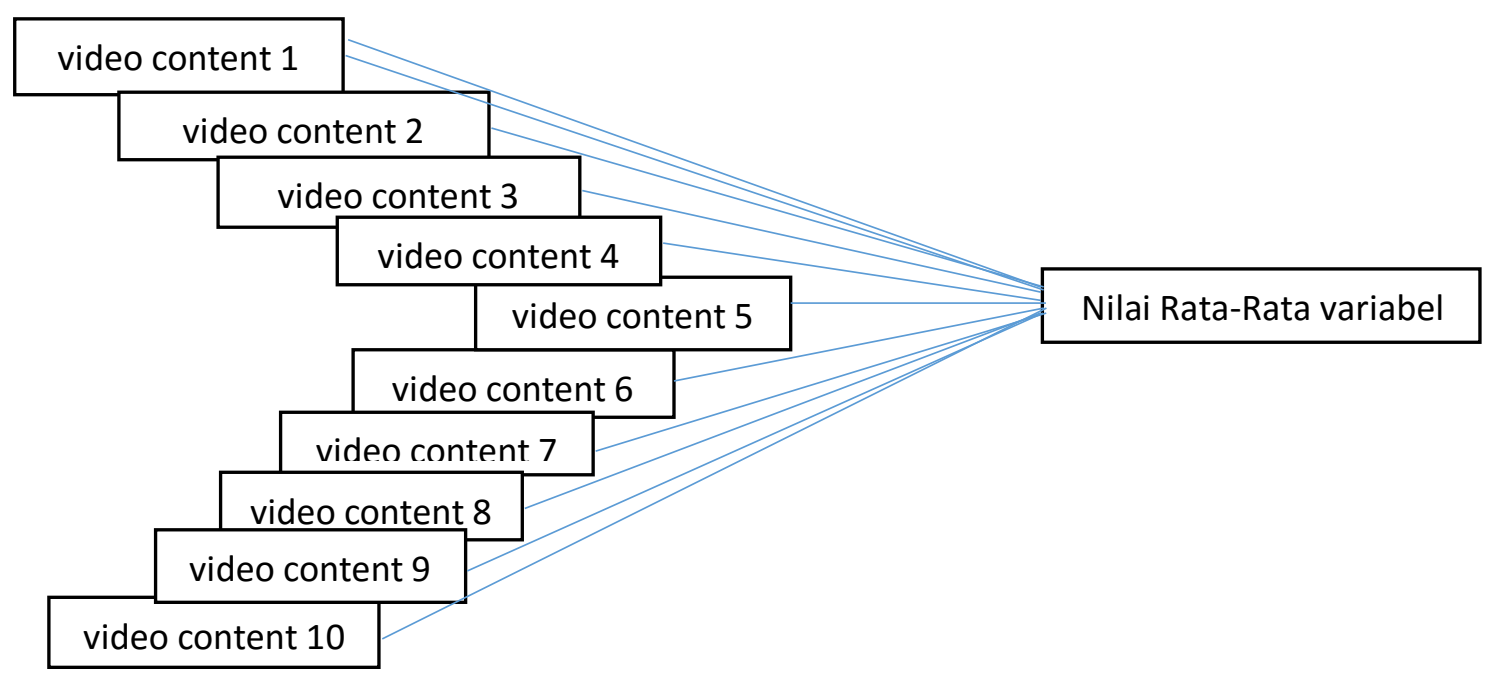

Gambar 1. Analisa Nilai Rata-Rata Variabel.

\section{Menghitung Nilai Kredibilitas Rasio}

Untuk menghitung nilai kredibilitas dari video comments to video views ratio, peneliti menggunakan cara membagi nilai variabel pertama dengan nilai variabel kedua. Jika video comments memiliki nilai 100 dan video views memiliki nilai 300, maka cara menghitungnya yaitu $100: 300=0,3$. Dengan begitu nilai dari video comments to video views ratio adalah 0,3 .

\section{Menentukan Peringkat Pada iPhone}

Pada langkah terakhir yang dilakukan pada penelitian ini yaitu menentukan peringkat pada masing-masing rasio yang ada. Pada penentuan peringkat perlu melihat karakteristik dari rasio yang di teliti. Jika karakteristik rasio merupakan rendah, maka objek yang memiliki nilai terendah akan mendapatkan angka 5 dan objek yang memiliki nilai tertinggi akan mendapatkan angka 1. Namun jika rasio memiliki karakteritik tinggi maka objek yang mendapatkan nilai tinggi akan mendapatkan angka 5 dan objek yang mendapatkan nilai terendah akan mendapatkan angka 1. Setelah mendapatkan hasil kredibilitas ratio maka dapat disimpulkan objek yang mana mendapatkan peringkat 1 sampai dengan peringkat 5 . 


\section{HASIL DAN PEMBAHASAN}

Dari data yang diperoleh melalui penyebaran kuesioner melalui youtube didapat informasi bahwa 57\% responden adalah laki-laki dan $43 \%$ responden adalah perempuan. Kategori usia didominasi oleh responden yang berumur 18-30 tahun yaitu sebesar $87 \%$. Tingkat pendidikan responden didominasi oleh S1-S3 (55\%). Pekerjaan responden didominasi oleh pelajar dan mahasiswa (62\%). Mayoritas pendapatan responden yaitu dibawah Rp $1.000 .000,00$ per bulan (45\%). Dan mayoritas responden berasal dari Bali dan Nusa Tenggara (43\%).

Rekomendasi iPhone terbaik 2021 diantaranya :

1. Phone 12 Pro/Max

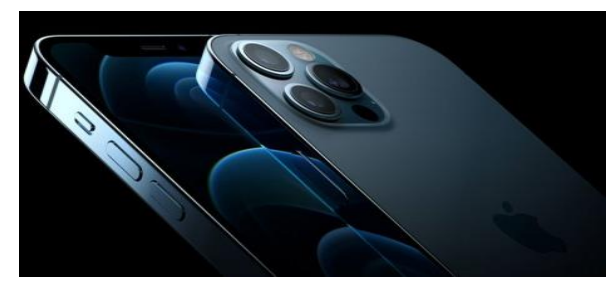

Phone 12 Pro/Max (foto: Apple)

sumber : https://review.bukalapak.com/gadget/rekomendasi-iphone-terbaik-110902

1. iPhone $12 /$ mini

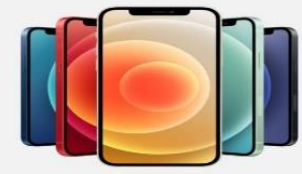

iPhone 12 (foto: Apple

sumber : https://review.bukalapak.com/gadget/rekomendasi-iphone-terbaik-110902

2. iPhone SE (2020)

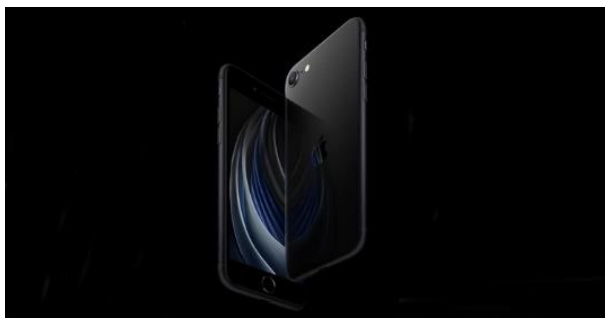

iPhone SE (2020) (foto: Apple)

sumber : https://review.bukalapak.com/gadget/rekomendasi-iphone-terbaik-110902

3. iPhone 8

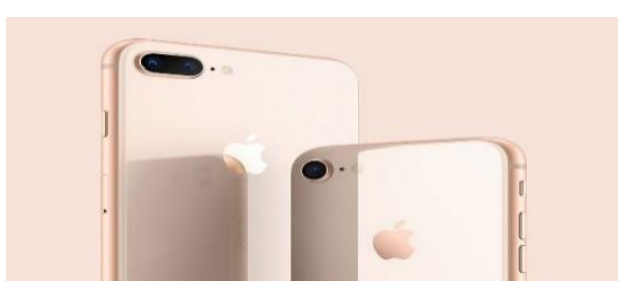

iPhone 8 (foto: Apple)

sumber : https://review.bukalapak.com/gadget/rekomendasi-iphone-terbaik-110902 
4. iPhone XR

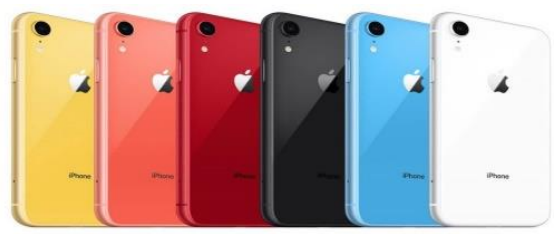

iPhone XR (foto: Apple)

sumber : https://review.bukalapak.com/gadget/rekomendasi-iphone-terbaik-110902

5. iPhone $\mathrm{X}$

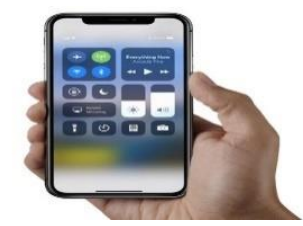

iPhone X (foto: Apple)

sumber : https://review.bukalapak.com/gadget/rekomendasi-iphone-terbaik-110902

6. iPhone 11

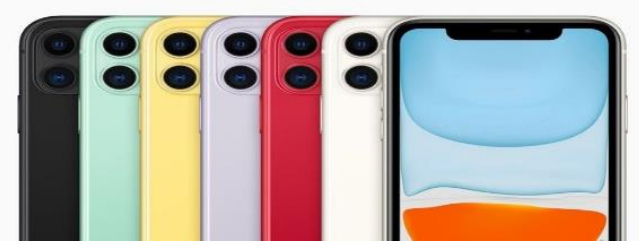

iPhone 11 (foto: Apple)

sumber : https://review.bukalapak.com/gadget/rekomendasi-iphone-terbaik-110902

7. iPhone 11 Pro

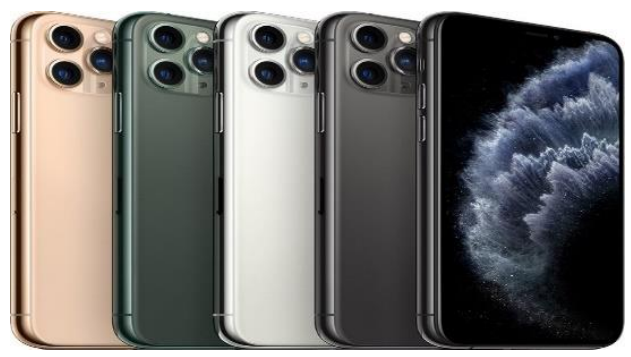

iPhone 11 Pro (foto: Apple)

sumber : https://review.bukalapak.com/gadget/rekomendasi-iphone-terbaik-110902

\section{Deskripsi data indikator variabel}

a. Variabel Youtube iPhone Review

Youtube iPhone Review merupakan pesan testimonial yang dilakukan oleh reviewer smartphone di YouTube yang memiliki pengetahuan lebih di bidang smartphone. Reviewer akan memakai smartphone dalam jangka waktu tertentu untuk mendapatkan kesaksian selama menggunakannya. Sehingga reviewer bisa mengungkapkan opini mengenai smartphone tersebut. Dalam review smartphone harus mampu menarik perhatian, menggunakan bahasa yang mudah dimengerti, 
menyampaikan pesan secara actual dan objektif sehingga membangkitkan kebutuhan responden, serta memberikan alternatif untuk mencapai kebutuhan. Hasil tanggapan dari orang yang mengisi kuesioner secara keseluruhan variable Youtube iPhone Review memiliki penilaian yang masuk kedalam kategori baik dimana ratarata jawaban responden menghasilkan nilai rata-rata. Artinya responden merasa bahwa pesan yang disampaikan oleh reviewer dapat diterima dengan baik yaitu :

Tabel 1. Analisa Nilai Rata-Rata Nilai Variabel Video Comments dan Video Views iPhone 12/Pro max

\begin{tabular}{|c|l|l|}
\hline No & $\begin{array}{c}\text { Video } \\
\text { Comment }\end{array}$ & $\begin{array}{c}|c| \\
\text { Video } \\
\text { Views }\end{array}$ \\
\hline 1 & 3.354 & 1.397 .241 \\
\hline 2 & 6.401 & 3.528 .887 \\
\hline 3 & 54 & 35.920 \\
\hline 4 & 21.000 & 5.9 .000 .000 \\
\hline 5 & 141 & 33.000 \\
\hline 6 & 5.000 & 1.8 .000 .000 \\
\hline 7 & 210 & 76.000 \\
\hline 8 & 147 & 56.000 \\
\hline 9 & 366 & 67.000 \\
\hline 10 & 1.000 & 187.000 \\
\hline Total & 37.673 & 5.381 .048 \\
\hline
\end{tabular}

Sumber : Pengolah Data Excel

Tabel 1. Analisa Nilai Rata-Rata Nilai Variabel Video Comments dan Video Views iPhone 12/mini

\begin{tabular}{|c|l|l|}
\hline No & $\begin{array}{c}\text { Video } \\
\text { Comment }\end{array}$ & Video Views \\
\hline 1 & 6.1 .000 & 2.3 .000 .000 \\
\hline 2 & 422 & 211.000 \\
\hline 3 & 45 & 133.000 \\
\hline 4 & 49 & 76.000 \\
\hline 5 & 120 & 17.000 \\
\hline 6 & 9 & 6.9 .000 \\
\hline 7 & 93 & 8.1 .000 \\
\hline 8 & 296 & 60.000 \\
\hline 9 & 144 & 16.000 \\
\hline 10 & 796 & 494.000 \\
\hline Total & 1974 & 1.007 .000 \\
\hline
\end{tabular}

Sumber : Pengolah Data Excel 
Tabel 1. Analisa Nilai Rata-Rata Nilai Variabel Video Comments dan Video Views iPhone SE (2020)

\begin{tabular}{|c|l|l|}
\hline No & $\begin{array}{c}\text { Video } \\
\text { Comment }\end{array}$ & Video Views \\
\hline 1 & 7.7 .000 & 3.1 .000 .000 \\
\hline 2 & 40 & 7.4 .000 \\
\hline 3 & 1 & 82 \\
\hline 4 & 11 & 1.5 .000 \\
\hline 5 & 479 & 1.8 .000 \\
\hline 6 & 641 & 120.000 \\
\hline 7 & 93 & 81.000 \\
\hline 8 & 1.5 .000 & 216.000 \\
\hline 9 & 1.000 & 279.000 \\
\hline 10 & 849 & 763.000 \\
\hline Total & 3.114 & 1.459 .082 \\
\hline \multicolumn{2}{|c|}{ Sumber : Pengolah Data Excel } \\
\hline
\end{tabular}

Tabel 1. Analisa Nilai Rata-Rata Nilai Variabel Video Comments dan Video Views iPhone 8

\begin{tabular}{|c|l|l|}
\hline No & $\begin{array}{c}\text { Video } \\
\text { Comment }\end{array}$ & Video Views \\
\hline 1 & 299.000 & 154.000 \\
\hline 2 & 667 & 200.000 \\
\hline 3 & 1.6 .000 & 686.000 \\
\hline 4 & 812 & 155.000 \\
\hline 5 & 142 & 279.000 \\
\hline 6 & 77 & 6.2 .000 \\
\hline 7 & 1.1 .000 & 1.5 .000 .000 \\
\hline 8 & 197 & 48.000 \\
\hline 9 & 72 & 4.4 .000 \\
\hline 10 & 447 & 44.000 \\
\hline Total & 301.414 & 1.566 .000 \\
\hline
\end{tabular}

Sumber : Pengolah Data Excel

Tabel 1. Analisa Nilai Rata-Rata Nilai Variabel Video Comments dan Video Views iPhone XR

\begin{tabular}{|c|l|l|}
\hline No & $\begin{array}{c}\text { Video } \\
\text { Comment }\end{array}$ & Video Views \\
\hline 1 & 8.3 .000 & 2.8 .000 .000 \\
\hline 2 & 562 & 88.000 \\
\hline 3 & 1.5 .000 & 530.000 \\
\hline 4 & 564 & 131.000 \\
\hline 5 & 508 & 55.000 \\
\hline 6 & 556 & 128.000 \\
\hline
\end{tabular}




\begin{tabular}{|c|l|l|}
\hline 7 & 329 & 55.000 \\
\hline 8 & 439 & 220.000 \\
\hline 9 & 771 & 248.000 \\
\hline 10 & 1.5 .000 & 999.000 \\
\hline Total & 3729 & 2.454 .000 \\
\hline \multicolumn{3}{|c|}{ Sumber : Pengolah Data Excel }
\end{tabular}

Tabel 1. Analisa Nilai Rata-Rata Nilai Variabel Video Comments dan Video Views iPhone X

\begin{tabular}{|c|l|l|}
\hline No & $\begin{array}{c}\text { Video } \\
\text { Comment }\end{array}$ & $\begin{array}{c}\text { Video } \\
\text { Views }\end{array}$ \\
\hline 1 & 21.000 & 6.1 .000 \\
\hline 2 & 141 & 422 \\
\hline 3 & 5.000 & 45 \\
\hline 4 & 210 & 5.9 .000 .000 \\
\hline 5 & 147 & 33.000 \\
\hline 6 & 366 & 1.8 .000 .000 \\
\hline 7 & 1.000 & 76.000 \\
\hline 8 & 6.1 .000 & 56.000 \\
\hline 9 & 422 & 67.000 \\
\hline 10 & 45 & 187.000 \\
\hline Total & 28.331 & 419.467 \\
\hline \multicolumn{2}{|l|}{ Sumber : Pengolah Data Excel }
\end{tabular}

Tabel 1. Analisa Nilai Rata-Rata Nilai Variabel Video Comments dan Video Views iPhone 11

\begin{tabular}{|c|l|l|}
\hline No & \multicolumn{1}{|c|}{$\begin{array}{c}\text { Video } \\
\text { Comment }\end{array}$} & \multicolumn{1}{|c|}{$\begin{array}{c}\text { Video } \\
\text { Views }\end{array}$} \\
\hline 1 & 422 & 33.000 \\
\hline 2 & 45 & 1.8 .000 .000 \\
\hline 3 & 49 & 76.000 \\
\hline 4 & 120 & 56.000 \\
\hline 5 & 9 & 67.000 \\
\hline 6 & 93 & 48.000 \\
\hline 7 & 5.000 & 4.4 .000 \\
\hline 8 & 210 & 44.000 \\
\hline 9 & 147 & 279.000 \\
\hline 10 & 366 & 763.000 \\
\hline Total & 6.461 & 1.366 .000 \\
\hline \multicolumn{3}{|c|}{ Sumber : Pengolah Data Excel }
\end{tabular}


Tabel 1. Analisa Nilai Rata-Rata Nilai Variabel Video Comments dan Video Views iPhone 11 Pro

\begin{tabular}{|c|l|l|}
\hline No & \multicolumn{1}{|c|}{$\begin{array}{c}\text { Video } \\
\text { Comment }\end{array}$} & \multicolumn{1}{|c|}{$\begin{array}{c}\text { Video } \\
\text { Views }\end{array}$} \\
\hline 1 & 564 & 82 \\
\hline 2 & 508 & 1.5 .000 \\
\hline 3 & 556 & 1.8 .000 \\
\hline 4 & 329 & 120.000 \\
\hline 5 & 439 & 81.000 \\
\hline 6 & 771 & 216.000 \\
\hline 7 & 11 & 60.000 \\
\hline 8 & 479 & 16.000 \\
\hline 9 & 641 & 494.000 \\
\hline 10 & 93 & 200.000 \\
\hline Total & 4391 & 1.187 .082 \\
\hline
\end{tabular}

Sumber : Pengolah Data Excel

Setelah menghitung nilai rata-rata tersebut, maka akan menemukan hasil akhir nilai rata-rata dari variabel video comments dan video views

Tabel 6. Nilai Variabel Pada Top 8 Rekomendasi iPhone Terbaik 2021

\begin{tabular}{|c|c|c|c|c|c|c|c|c|}
\hline Variable & $\begin{array}{l}\text { iPhone } 12 \\
\text { Pro/Max }\end{array}$ & $\begin{array}{l}\text { iPhone } \\
12 / \text { mini } \\
\end{array}$ & $\begin{array}{c}\text { iPhone SE } \\
(2020)\end{array}$ & iPhone 8 & iPhone XR & iPhone X & iPhone 11 & $\begin{array}{c}\text { iPhone } 11 \\
\text { Pro }\end{array}$ \\
\hline $\begin{array}{l}\text { Video } \\
\text { Comments }\end{array}$ & 37.673 & 1974 & 3.114 & 301.414 & 3729 & & 6.461 & 4391 \\
\hline $\begin{array}{l}\text { Video } \\
\text { Views }\end{array}$ & 5.381 .048 & 1.007 .000 & 1.459 .082 & 1.566 .000 & 2.454 .000 & 419.467 & 1.366 .000 & 1.187 .082 \\
\hline
\end{tabular}

Sumber : Pengolah Data Excel

Pada rekomendasi iPhone terdapat 57 rasio yang relevan digunakan untuk mengukur kredibilitas pada masing-masing iPhone. Namun pada penelitian kali ini hanya berfokus untuk menghitung Video Comments to Video Views Ratio. Untuk menghitung kredibilitas dari masing-masing iPhone setiap vendor smartphone, peneliti menghitung dengan cara : variabel 1 akan dibagi dengan variabel 2 , sehingga ditemukan hasil analisisa dari rasio tersebut.

Tabel 7. Hasil Perhitungan Rasio iPhone

\begin{tabular}{|c|c|c|c|c|c|c|c|c|c|}
\hline No & RATIO & $\begin{array}{l}\text { iPhone } 12 \\
\text { Pro/Max }\end{array}$ & $\begin{array}{l}\text { iPhone } \\
12 / \text { mini }\end{array}$ & $\begin{array}{c}\text { iPhone SE } \\
(2020) \\
\end{array}$ & iPhone 8 & $\begin{array}{c}\text { iPhone } \\
\text { XR }\end{array}$ & iPhone X & iPhone 11 & $\begin{array}{c}\text { iPhone } 11 \\
\text { Pro }\end{array}$ \\
\hline 1 & $\begin{array}{c}\text { Video } \\
\text { Comments } \\
\text { to Video } \\
\text { Views } \\
\text { Ratio }\end{array}$ & 0,007001053 & 0,001960278 & 0,002134219 & 0,192473819 & 0,00151956 & 0,067540474 & 0,00472987 & 0,003698986 \\
\hline & & 1 & 1 & 3 & 3 & 1 & 1 & 5 & 5 \\
\hline
\end{tabular}

Video Comments to Video Views Ratio memiliki karakteristik yang tinggi, artinya semakin tinggi nilai yang dihasilkan maka semakin baik kredibilitas dari performa akun tersebut. Untuk memberikan peringkat pada masing-masing Smartphone, peneliti memberikan angka 5 kepada 
Smarthphone yang mendapatkan nilai tertinggi dan angka 1 untuk smartphone yang mendapatkan nilai terendah. Berikut merupakan tabel urutan nilai yang dihasilkan oleh masingmasing smartphone.

Tabel 8. Nilai Rasio Top 8 iPhone Terbaik 2021

\begin{tabular}{|c|c|c|c|c|c|c|c|c|}
\hline \multicolumn{9}{|c|}{ Nilai } \\
\hline Karakteristik & $\begin{array}{l}\text { iPhone } 12 \\
\text { Pro/Max }\end{array}$ & $\begin{array}{l}\text { iPhone } \\
12 / \text { mini }\end{array}$ & $\begin{array}{c}\text { iPhone SE } \\
(2020)\end{array}$ & $\begin{array}{l}\text { iPhone } \\
8 \\
\end{array}$ & $\begin{array}{c}\text { iPhone } \\
\text { XR }\end{array}$ & $\begin{array}{c}\text { iPhone } \\
x\end{array}$ & iPhone 11 & $\begin{array}{c}\text { iPhone } 11 \\
\text { Pro }\end{array}$ \\
\hline Tinggi & 1 & 1 & 3 & 3 & 1 & 1 & 5 & 5 \\
\hline
\end{tabular}

Sumber : Pengolah Data Excel

Dari Tabel Nilai Rasio Top 8 iPhone terbaik 2021 dapat simpulkan bahwa iPhone 11 mendapatkan nilai tertinggi untuk rasio Video Comments to Video Views. Sedangkan iPhone $\mathrm{X}$ dan iPhone 12 mendapatkan nilai terendah untuk rasio ini. Jadi, pada penelitian ini iPhone 11 memiliki kredibilitas performa yang lebih baik dibandingkan dengan smartphone yang lainnya.

\section{Hasil Analisis Data}

Hasil analisis data dari uji instrumen yang pertama yaitu uji validitas. Suatu kuesioner dikatakan valid jika pertanyan pada kuesioner mampu untuk mengungkapkan sesuatu yang akan diukur oleh kuesioner tersebut dan jika $r$ hitung > $r$ tabel dengan tingkat signifikansi 5\%

\begin{tabular}{|c|c|c|c|c|}
\hline Variabel & \multicolumn{3}{|c|}{ Pernyataan } & Keterangan \\
\hline $\begin{array}{c}\text { Youtube iPhone } \\
\text { Review }\end{array}$ & & $\begin{array}{c}\text { Video } \\
\text { Comments }\end{array}$ & $\begin{array}{l}\text { Video } \\
\text { Views }\end{array}$ & \\
\hline & $\begin{array}{c}\text { iPhone } 12 \\
\text { Pro/Max }\end{array}$ & 37.673 & 5.381 .048 & Valid \\
\hline & $\begin{array}{l}\text { iPhone } \\
\text { 12/mini }\end{array}$ & 1974 & 1.007 .000 & Valid \\
\hline & $\begin{array}{c}\text { iPhone SE } \\
(2020)\end{array}$ & 3.114 & 1.459 .082 & Valid \\
\hline & iPhone 8 & 301.414 & 1.566 .000 & Valid \\
\hline & iPhone XR & 3729 & 2.454 .000 & Valid \\
\hline & iPhone X & 28.331 & 419.467 & Valid \\
\hline & iPhone 11 & 6.461 & 1.366 .000 & Valid \\
\hline & $\begin{array}{c}\text { iPhone } 11 \\
\text { Pro }\end{array}$ & 4391 & 1.187 .082 & Valid \\
\hline
\end{tabular}




\section{KESIMPULAN}

Tujuan dari penelitian ini adalah mengetahui kredibilitas performa dari iPhone Top 8 Rekomendasi iPhone 2021 menggunakan Video Comments to Video Views Ratio. Top 8 iphone tersebut diantaranya : iPhone 12 promax, iPhone 12/mini, iPhone SE (2020), iPhone 8, iPhone XR, iPhone X, iPhone 11, iPhone 11 Pro.

Dari 8 vendor smartphone tersebut dapat disimpulkan bahwa :

- Peringkat pertama diraih oleh vendor iPhone 11 dengan nilai tertinggi yaitu 0.00472987

- Sedangkan iPhone X dan iPhone 12 mendapatkan nilai terendah untuk rasio ini. Jadi, pada penelitian ini iPhone 11 memiliki kredibilitas performa yang lebih baik dibandingkan dengan smartphone yang lainnya. 


\section{DAFTAR PUSTAKA}

https://review.bukalapak.com/gadget/rekomendasi-iphone-terbaik-110902 http://repository.unair.ac.id/87146/5/JURNAL\%20_NADYAH\%20PERMITASARI_071511533 095\%20.PDF.pdf

https://arekubl.blogspot.com/2014/05/sejarah-penemu-iphone-pertama-kali.html https://id.wikipedia.org/wiki/Apple_Inc. 